\title{
BMJ Open Identifying hearing care access barriers among older Pacific Island people in New Zealand: a qualitative study
}

\author{
Ravi Reddy, ${ }^{\oplus}$ David Welch, ${ }^{1}$ leti Lima, ${ }^{2}$ Peter Thorne, ${ }^{1}$ Vili Nosa $^{2}$
}

To cite: Reddy R, Welch $D$, Lima I, et al. Identifying hearing care access barriers among older Pacific Island people in New Zealand: a qualitative study. BMJ Open 2019;9:e029007. doi:10.1136/ bmjopen-2019-029007

Received 09 January 2019 Revised 03 July 2019 Accepted 23 July 2019

\section{Check for updates}

(c) Author(s) (or their employer(s)) 2019. Re-use permitted under CC BY-NC. No commercial re-use. See rights and permissions. Published by BMJ.

${ }^{1}$ Section of Audiology, University of Auckland, Auckland, New

Zealand

${ }^{2}$ Section of Pacific Health, University of Auckland, Auckland, New Zealand

Correspondence to

Dr Ravi Reddy;

r.reddy@auckland.ac.nz

\section{ABSTRACT}

Objectives Hearing loss is one of the most prevalent conditions affecting older people. In addition, there is little known about the factors influencing the uptake of hearing services among underserved communities. Our objective was to identify the barriers to accessing hearing care services among older Pacific Island people in New Zealand.

Settings Eligible participants from Auckland City, New Zealand.

Participants Individual face-to-face in-depth interviews were conducted with 36 older Pacific Island people who were experienced hearing difficulties.

Methods A Pacific Island research methodology (Talanoa) and the 'Health Care Access Barriers' (HCAB) model, which identifies modifiable barriers to healthcare, was used as a theoretical framework for this research. The interviews were transcribed and analysed using a deductive approach to identify HCAB themes and subthemes experienced by older Pacific Island people.

Results Identified themes aligned with HCAB's themes of financial, structural and cognitive barriers and subthemes described Pacific Island perspectives related to hearing care access in New Zealand. The financial barriers related to the high cost of hearing care and the structural barriers included transportation difficulties, limited family support, preference for community-based services and the absence of hearing care delivered by family doctors. Community norms and attitudes, communication limitations and limited awareness of hearing care services formed cognitive barriers among older Pasifika people in this study.

Conclusion We identified financial, structural and cognitive barriers that dissuaded older Pasifika people from accessing hearing care services. These modifiable barriers need to be eliminated or minimised to enable people to readily receive the hearing care assistance they need. It is essential to improve and develop culturally responsive models of hearing service delivery to ensure equitable access to hearing care, especially for underserved groups such as Pacific Island communities.

\section{INTRODUCTION}

Hearing loss is one of the most prevalent conditions influencing the quality of life of older people in our communities. ${ }^{1}$ Hearing deteriorates naturally with age, ${ }^{2}$ undermining the most crucial sense for communication

\section{Strengths and limitations of this study}

This is the first study to investigate barriers influencing hearing care access among older Pacific Island people in New Zealand.

- In addition, this research was guided by a Pacific Island research methodology that acknowledged Pacific Island cultural responsiveness.

- This study provides a foundation to inform and develop policies and strategies aimed at ensuring equitable hearing care for underserved groups like older Pacific Island people.

- The main limitation of this study is that its sampling frame reflected an urban demographic from one city. Further studies including participants from other areas may establish whether differences exist.

and social interaction and it also exacerbates other burdens carried by older people. ${ }^{3}$ It is estimated that hearing impairment significantly affects $22 \%$ of people aged over 65 years, compared with $7.5 \%$ aged over 15 years in New Zealand. ${ }^{4}$ The severity and incidence increase as people age beyond 65 years. ${ }^{5}$ The number of people with hearing loss among this demographic in New Zealand is expected to double in the next 50 years. ${ }^{4}$ This will include $9.2 \%$ of people of Pacific Island ethnicity (Pasifika), compared with $4.7 \%$ in 2013. 'Pasifika' is a term used throughout this article when referring to people of Pacific Islands ethnicities. ${ }^{7}$

Pasifika people experience a higher burden of poor health outcomes and poorer access of healthcare compared with non-Pasifika people New Zealand. This has been attributed to health inequalities resulting from socioeconomic determinants such as higher unemployment rates, fewer economic resources and lower than average income levels. ${ }^{8}$ There are limited data and information about hearing loss among Pasifika people in New Zealand. The factors that affect access to hearing health services and the delivery of services need to be better understood in 
order to improve hearing-related outcomes of Pasifika peoples.

The aim of this research was to identify barriers to hearing care access experienced by older (65 years of age and greater) Pasifika people. The Health Care Access Barriers (HCAB) model $^{9}$ is used as the theoretical framework for this research. The HCAB model is a framework that identifies and targets modifiable healthcare access barriers that limit healthcare setting-patient interactions. It describes three categories of modifiable healthcare access barriers (financial barriers, which includes the cost of treatment; structural, which includes the organisational barriers; and cognitive barriers, which include inadequate information, prejudices, communication and so on). It is argued that these barriers are associated with decreased screening, late presentation to care, and lack of treatment, which in turn result in poor health outcomes and health disparities. Overcoming these disparities requires improved understanding of the factors that influence the uptake of hearing care among older Pasifika people.

\section{MATERIALS AND METHODS Design}

A qualitative research methodology was used, with semistructured interviews conducted to allow an in-depth exploration of the perceptions, attitudes and personal experiences related to hearing care services among older Pasifika people. A phenomenological and collaborative story-telling approach was selected to explore people's experiences within a Pasifika context and was focused on the issues as experienced and lived by the participants. ${ }^{10}$ The Talanoa research methodology was used to allow participants to have a more meaningful engagement in the research process by ensuring cultural appropriateness, and encouraging the flow of stories and ideas during the interviews. ${ }^{11}$ This Pasifika research methodology ensured that there was respect, understanding and trust between the researchers and participants. As it is a feature of the Talanoa methodology, Research Assistants (two males; three females) who were fluent in the Pacific language of the interviewee and were culturally knowledgeable conducted the interviews. All research assistants undertook a half-day training session conducted by the lead researcher on how to interview participants. This included the importance of the Talanoa methodology, tips and practice sessions. The study conformed to the principles embodied in the Declaration of Helsinki.

\section{Participants}

To be eligible, participants had to identify with a Pasifika ethnicity, indicate that they were at least 65 years old and were experiencing hearing difficulties. Participants were selected from both genders and included those who had sought hearing care assistance and those who had not.

\section{Recruitment}

Recruitment was conducted using snowball sampling techniques ${ }^{12}$ facilitated through networks between the investigators, audiology clinics and community organisations. Advertisements were circulated to these organisations to promote the study. In addition, a news article was published in a local community newspaper, which generated interest and offers to participate in this study. The participants contacted the research team to express interest in participating. The study was explained and participant information sheets distributed before each participant signed an informed consent form. The participants had the option of choosing the participant information sheet and consent form in their preferred Pasifika language. All participants received a NZ $\$ 50$ grocery voucher as a gratitude for their time and assistance.

\section{Data collection}

Data were collected through face to face semistructured interviews that took place with individual participants and a Pasifika language speaking research assistant at participant's homes or at a public place convenient to the participant. Interviews took between 30 and $45 \mathrm{~min}$ to complete. No one else was present during the interviews to maintain privacy. An audio recording was made with a dictaphone and the audio data files were saved to password-protected computers. Interviews were transcribed, and those conducted in Pasifika languages were translated by the research assistants into English. All transcripts were returned to the participants for comment or correction and no alterations or repeat interviews were needed. Participants were recruited until theoretical saturation was achieved ${ }^{12}$ and no new information was emerging.

\section{Coding and thematic analysis}

Thematic analysis was undertaken using the six phase steps described by Braun and Clarke. ${ }^{13}$ This included familiarisation with data content and the generation of codes that described features of the data. The lead author did the coding of the transcripts. A deductive approach was used where the lead author created a coding structure based on the HCAB model. Multiple coders were not used to corroborate the codes. However, the research team reviewed and edited themes and subthemes for suitability and labelling. We explored if other terms could offer better description of the themes. These themes and codes were validated through consensus of the research group. NVivo V.12 software was used to conduct the coding and label themes.

\section{Patient and public involvement}

Patients and/or public were not involved.

\section{RESULTS}

Thirty-six participants were selected from both genders (male-17; female-19) and included those who had sought 
hearing care assistance $(n=16)$ and those who had not $(n=20)$. Eight participants were of Samoan, Tongan and Cook Island Maori ethnicities, and six each of Niuean and Fijian ethnicities. All participants were from Auckland, New Zealand.

\section{Financial barriers}

\section{Hearing care is expensive}

The participants described how the perceived high costs and a sense of embarrassment for not being able to afford hearing care services discouraged them from seeking assistance.

Some people panic when there is no money to buy the thing to put on their ear because it is too expensive to buy them. It is in the thousands and people cannot afford it. So, they just sit around and not worry about it and seek help.

I also think that prices need to be reasonable and affordable to our Pasifika elders. So that our people are not ashamed to seek help and not reluctant because they are poor.

\section{Structural barriers}

Structural barriers related to the difficulties older Pasifika people faced when physically visiting service delivery organisations despite their desire to seek assistance. This was justified by their desire to have local community-based services. In addition, the participants questioned the role of family doctors in promoting in promoting hearing care.

\section{Transportation difficulties}

The lack of personal transportation and the inability to drive was reported as reason for not accessing services, even if they wish to seek assistance.

Older Pasifika people do not seek help is because they do not have cars, they cannot drive themselves to the doctors.

\section{Limited family support}

The absence of family assistance was reported as a reason for not seeking hearing care services. The participants discussed the reliance on family members, mostly their offspring, to get them to service providers. They hoped family members would transport them to seek assistance. They reported that they need family members to communicate for them in the English language. It appears that the presence of family members supported participants emotionally.

The only thing for you to be able to go is if there was someone in the family who can speak well and can take us. If not, no way I can go see the doctor. I am embarrassed/shy of going because I cannot speak well.
The participants reported that while it is in their culture for younger generations to support and care for their elderly, times have changed.

There is a big change in times. In those days, while I was growing up, parents were the first and main priority of their children but nowadays, children get brainy, get blessed, and then they stop caring for their parents. They stop giving their time for their parents because they are busy with other things.

\section{Preference for community-based services}

Older Pasifika people reported that they would be more comfortable with a service that could come to them rather than them having to go out and seek assistance.

I have always thought about it but I think it is easier and better if there are people that came around to the house to check up on people's ears and their health. It just makes it easier.

\section{Expectation of family doctors}

The participants reported that family doctors could take a more active role in supporting them to seek assistance for their hearing difficulties. It was relayed that family doctors could talk to them about their hearing when conducting routine examinations.

When I used to visit my doctors on a monthly basis for my check-ups, they never checked my ears, despite me having ear problems.

It is not like my doctor checks my ears when I go to see him. That made me think that my ears were fine.

\section{Cognitive barriers}

Cognitive barriers identified in this study were those associated to Pasifika community norms, communication limitations and the lack of awareness of accessible hearing care services and funding on offer.

\section{Community norms and attitudes}

There appears to be the attitude of not acknowledging the severity of hearing difficulties among older Pasifika people. This attitude may influence people to defer seeking hearing care intervention to much later.

It is like they wait until their condition is worse or very bad, that is when they will start to seek help.

The participants described a culture of diffidence among Pasifika people, where they regard themselves as shy and reserved. Their lack of engagement with hearing health services could be because of the perceived fear of stigmatisation, being mocked and having perceptions of criticism or rejection.

This is also the first time I am speaking about this. I am really ashamed to speak about my hearing loss.

I know that I do not tell people that I have hearing aids on because I know that if I tell them then they 
would jokingly make remarks and tease me about the situation.

There was also the emergence of a sub-theme that explored religious beliefs about impairment among older Pasifika people. There is a belief that it is God's will that one has hearing impairment and that only God can fix it.

I am a strong believer that whatever happens to me is the will of God. I always pray, and beg God to show me ways so that I can get better. Remember always, that the doctor of all doctors is God.

\section{Communication limitations}

The participants described how having limited English, the service workforce having limited or no capacity to converse in Pasifika languages and the absence of interpreter services reasons for not seeking assistance.

Doctors need to be able to speak Pasifika languages. Language is huge barrier for us older Pasifika people.

It is easier to talk in our language and maybe that is the reason why our elderly people are like that (not seeking services).

Interpreters are really important. For Pasifika people with no children, maybe an interpreter at the doctors can help.

\section{Awareness of available hearing care services and funding}

The participants suggested that there was little awareness of hearing care services offered. It appears that older Pasifika people do not understand what services are available and have difficulty understanding existing information.

Older people do not really have any knowledge of services that exist that they are able to seek out for help and there is very little communication on who can help and where help can be found so they are left on their own to find it out themselves.

In addition, people do not know of existing financial assistance schemes to help them access hearing care services. This demotivates older Pasifika people who are already put off by the high costs to access assistance for the hearing difficulties.

If there was a scheme to subsidise the cost of hearing aids it would be better especially for those that have work related issues with hearing.

\section{DISCUSSION}

\section{Summary of the results}

We identified Pasifika perspectives of financial, structural and cognitive barriers to hearing care access. Cognitive access barriers that may, alone or in combination, adversely affect access to hearing care services may further compound financial and structural barriers.

\section{Comparison with the existing literature}

Cost remains a reason for deferring primary care in New Zealand. ${ }^{14}$ Older Pasifika people believe that the financial costs associated with accessing hearing care is too expensive. This has been reinforced by their own experiences and that of others. The NZ hearing healthcare sector is mostly administered by privately owned audiology practices (for adult hearing loss) and the public sector (for paediatric hearing loss and medical conditions). For adults, the audiology practices often provide free hearing screening testing, and the costs are bundled into the price of hearing aids when purchased. Patients are required to pay, as a copayment fee, on average NZ $\$ 1500$ to acquire hearing aids and a further cost of approximately NZ $\$ 165$ for maintenance services. ${ }^{15}$ Older Pasifika people were unaware of financial support schemes available to help people access services. The NZ government provides funding via several schemes that will either partially or fully fund a person's hearing aids depending on the cause of the loss and their situation. There are funding options such as hearing aid government subsidy of NZ $\$ 511$ per ear, possible government funding for eligible occupational hearing loss and social welfare deductible loans of NZ $\$ 1000$ to assist with purchasing hearing aids. ${ }^{16}$ Our findings suggest that financial barriers to hearing care services is not exclusive to low/middle-income countries. ${ }^{17}$

Transportation to service providers was a structural barrier identified in this study that could be modified to some extent. This could be in the form of service provider-led transportation service, subsided transportation costs and the provision of local community-based services. This could also be extended to family members who act as support resource for older Pasifika people. Family connectedness has been seen as an integral part of the Pasifika lifestyle, where there is interdependence between individuals ${ }^{18}$ and implicit in this would be the understanding that the younger family members would look after the elderly. However, this way of living may be changing owing to busy work commitments and the negative impact and challenge of New Zealand mainstream culture on the younger Pasifika generation. ${ }^{18} 19$

It also appears that family doctors who routinely examine older Pasifika people for other ailments are trusted to flag hearing issues. There is a perception among older Pasifika people that doctors should talk to their patients about the state of their hearing and refer them to appropriate hearing care services if needed. This may not specifically relate to hearing but general healthcare. A survey exploring patient expectations of doctors found that there was high agreement that doctors should know patient health issues and coordinate necessary care over time..$^{20}$ This may be something to consider for health policy makers as doctors have a greater access to people seeking assistance for conditions unrelated to hearing.

Cognitive barriers included community norms and attitudes having a negative influence on the uptake of hearing services. There may be an attitude of denial or 
minimising the severity of hearing impairment in the community. This attitude corroborates other evidence that people defer hearing care intervention for up to ten years following the onset of their hearing problems. ${ }^{21}$ Pasifika people regard themselves as shy and reserved, and individuals fear being subjected to ridicule and stigma. Personal ailments are therefore private, and a feeling of embarrassment prevents them from acknowledging their hearing difficulties and older Pasifika may not want to emotionally and financially burden their loved ones with their problems. ${ }^{18}{ }^{19}$ In addition, a religious or spiritual belief that hearing difficulties is God's will and only God can heal them has dissuaded older Pasifika people from accessing medical care. Pasifika people have a holistic view of health where a positive and balanced relationship with God, people and the environment are regarded as paramount to achieving health and well-being. ${ }^{18}$ Spirituality may be used as a motivator to seek hearing care assistance and may require the influence of religious leaders in the community.

Linguistic barriers together with the absence of interpreter assistance negatively influence older Pasifika people's experience when engaging with hearing care services. Language barriers and monocultural assumptions and practices of healthcare professionals and healthcare service providers are known to be barriers to healthcare access among older Pasifika people. ${ }^{19}$ Hearing service providers should ensure that services and policies are culturally responsive to Pasifika needs and are entrenched in community settings such as churches and local organisations. Given the other barriers identified in the hearing sector, and the growing numbers of Pasifika people with age-related hearing loss, this barrier may be the most easily addressed by audiology practices.

\section{Strengths and limitations}

The strength of this research is that it is the first to look at hearing care access among older Pasifika people in New Zealand. In addition, it was guided by a Pasifika research methodology that responded to Pasifika cultural responsiveness, interviews were conducted in appropriate languages by culturally appropriate researchers, and the analysis had a strong theoretical basis through the HCAB model, which led to insights that will allow practical changes to the hearing health service. The main limitation of this study is that its sampling frame reflected an urban demographic from one city. There are Pasifika communities in other parts of the country that may not be representative of this sample. Further studies in these other groups may establish whether differences exist.

\section{Implications for policy, practice and future research}

The findings of this research provide an important foundation to improve the uptake of hearing health services. The modifiable financial, structural and cognitive factors identified need to be targeted to minimise and or eliminate its influence on hearing service seeking behaviour. It appears that these factors can also be interconnected.
As such, the development of multilevel interventions may be needed to promote hearing care among older Pasifika people. These interventions need to collectively target the financial, structural and cognitive factors. There could be a tailored awareness programme targeting Pacific Island communities promoting hearing care and providing information that supports people to seek assistance. There appears to be an opportunity to incorporate hearing care services into existing Pasifika healthcare facilities. This may alleviate concerns of transportation costs to get to another service provider and provide motivation to attend a facility people are familiar with. Until the development of such integrated services, hearing service delivery needs to recognise Pacific Island cultural responsiveness in their practice to motivate people to seek assistance. Future research should be aimed at testing community-based interventions that motivate people to seek hearing care services.

\section{CONCLUSION}

This study adds much-needed information and provides information to improve hearing care outcomes for the underserved Pasifika communities in New Zealand. It raises important questions about awareness, affordability and ease of access related to hearing care services. It is a public health failure that modifiable barriers deny access for essential hearing care services to underserved communities, even in high-income countries. The combination of these factors eventually contributes to poor hearing-health outcomes and health disparities. There needs to be further research and evidence-based development of interventions that mitigate these barriers to enable people to readily receive the hearing care assistance they need. It is essential to improve and develop culturally responsive models of hearing service delivery to ensure equitable access to hearing care, especially for underserved groups such as Pasifika communities.

Acknowledgements The authors wish to thank and acknowledge all of the people who gave their time as participants in this study. We thank Sili Pita, Evan Teiti, Temo Nemani, Braydon Kulatea, Latasi Koro and Mele Takai who conducted the interviews for the Auckland team. We would also like to thank the Vaka Tautua Organisation and its Chief Executive, Mr Vui Mark Gosche for their support and assistance.

Contributors All authors have contributed significantly in this research work. The authors (RR, DW, IL, PT and VN) significantly contributed in the study design and the critical review of the manuscript. The principal investigator (RR) collected, analysed, interpreted the data and wrote the first draft of the manuscript. The authors (DW, IL, PT and VN) highly contributed in the analysis and interpretation of data. Final approval was given by all authors.

Funding This work was supported by The Health Research Council of New Zealand Pacific Postdoctoral Fellowship Grant, grant number (16/508) awarded to the lead author.

Competing interests None declared.

Patient consent for publication Not required.

Ethics approval Ethics approval was obtained from the University of Auckland Ethics Committee (Ref: UAHPEC-016878). Written consent has been obtained from all interviewees to participate after giving them brief explanations about the purpose of the study. The study participants were informed about their right to participate or not to participate in the study. 
Provenance and peer review Not commissioned; externally peer reviewed.

Data availability statement Data are available upon reasonable request.

Open access This is an open access article distributed in accordance with the Creative Commons Attribution Non Commercial (CC BY-NC 4.0) license, which permits others to distribute, remix, adapt, build upon this work non-commercially, and license their derivative works on different terms, provided the original work is properly cited, appropriate credit is given, any changes made indicated, and the use is non-commercial. See: http://creativecommons.org/licenses/by-nc/4.0/.

\section{REFERENCES}

1. Cruickshanks KJ, Wiley TL, Tweed TS, et al. Prevalence of hearing loss in older adults in Beaver dam, Wisconsin. The epidemiology of hearing loss study. Am J Epidemiol 1998;148:879-86.

2. Schuknecht HF, Gacek MR. Cochlear pathology in presbycusis. Ann Otol Rhinol Laryngol 1993;102:1-16.

3. Dalton DS, Cruickshanks KJ, Klein BEK, et al. The impact of hearing loss on quality of life in older adults. Gerontologist 2003;43:661-8.

4. Exeter DJ, Wu B, Lee AC, et al. The projected burden of hearing loss in New Zealand (2011-2061) and the implications for the hearing health workforce. N Z Med J 2015;128:12-21.

5. Gates GA, Mills JH. Presbycusis. Lancet 2005;366:1111-20.

6. Zealand SN. National ethnic population projections: 2013(base)-2038 update. Wellington: New Zealand Government, 2015.

7. Ministry of Education. Pasifika in New Zealand Wellington: New Zealand government. Available: http://pasifika.tki.org.nz/LEAP/ Pasifika-in-New-Zealand [Accessed 24 Nov 2018].

8. Southwick M, Timothy K, Debbie R. Primary care for Pacific people : a Pacific and health systems approach : report to the Health Research Council and the Ministry of Health. Wellington: Pacific Perspectives, 2012.

9. Carrillo JE, Carrillo VA, Perez HR, et al. Defining and targeting health care access barriers. J Health Care Poor Underserved 2011;22:562-75.
10. Suaalii-Sauni T, Fulu-Aiolupotea SM, research DP. Decolonising Pacific research, building Pacific research communities and developing Pacific research tools: the case of the talanoa and the faafaletui in Samoa. Asia Pac Viewp 2014:55:331-44.

11. Vaioleti TM. Talanoa research methodology: a developing position on Pacific research. Waikato Journal of Education 2006;12:21-34.

12. Creswell JWLos Angeles: S, ed. Qualitative inquiry \& research design : choosing among five approaches. Fourth edition, 2018.

13. Braun V, Clarke V. Using thematic analysis in psychology. Qual Res Psychol 2006;3:77-101.

14. Jatrana $S$, Crampton P. Primary health care in New Zealand: who has access? Health Policy 2009;93:1-10.

15. Deloitte Access Economics. Listen hear! New Zealand: social and economic costs of hearing loss in New Zealand: a report by Deloitte access economics Pty LTD prepared for the National foundation for the deaf Inc, 2017.

16. Ministry of Health. Guide to getting hearing AIDS: hearing aid subsidy scheme New Zealand. Available: https://www.health.govt.nz/ publication/guide-getting-hearing-aids-hearing-aid-subsidy-scheme [Accessed 22 Nov 2018].

17. Olusanya BO, Neumann KJ, Saunders JE. The global burden of disabling hearing impairment: a call to action. Bull World Health Organ 2014;92:367-73.

18. Lui D. Family - a Samoan perspective. supporting families conference. Wellington, NZ: Mental Health Commission, 2003.

19. Tamasese T, Parsons T, Waldegrave C. Pacific perspectives on ageing in New Zealand: Pacific-focussed qualitative research. prepared for the New Zealand longitudinal study of ageing (NZLSA), family centre social policy research unit. Wellingotn: Massey University, 2014.

20. Old A, Adams B, Foley P, et al. Society's expectation of the role of the doctor in New Zealand: results of a national survey. $N Z$ Med J 2011;124:10-22.

21. Davis A, Smith P, Ferguson M, et al. Acceptability, benefit and costs of early screening for hearing disability: a study of potential screening tests and models. Health Technol Assess 2007;11. 